\title{
Direct bacterioscopic observation of Helicobacter in the oral cavity, stomach
}

\section{and rectum: Immunocytochemical study}

\author{
Viacheslav Kravtsovv,2, Maria Taame ${ }^{3,2}$, and Boris Gumilevskiy ${ }^{2}$
}

1. Nikiforov Russian Center of Emergency and Radiation Medicine, EMERCOM, Saint-Petersburg, Russian Federation

2. S.M. Kirov Military Medical Academy, Saint-Petersburg, Russian Federation

3. University of Eastern Finland, Institute of Public Health and Clinical Nutrition, Finland

\section{RESEARCH}

Please cite this paper as: Kravtsov V, Taame M, Gumilevskiy B. Direct bacterioscopic observation of Helicobacter in the oral cavity, stomach and rectum: Immunocytochemical study. AMJ 2018;11(2):64-73.

https://doi.org/10.21767/AMJ.2017.3247

\section{Corresponding Author:}

Viacheslav Kravtsov

Nikiforov Russian Center of Emergency and Radiation Medicine, EMERCOM, Saint-Petersburg

Russian Federation

Email: kvyspb@mail.ru

\section{ABSTRACT}

\section{Background}

Bacterial cells of Helicobacter Pylori (HP) are often found in people with chronic gastritis and peptic ulcer disease (PUD). All patients with symptoms are usually screened for HP bacterial cells by different methods of detection. Studies have shown that HP can colonize the stomach and other parts of the gastorointestinal tract such as the oral cavity and rectum.

\section{Aims}

To visualize and evaluate the bacterial cells of Helicobacter Pylori in vivo in the gastric, oral and rectal mucosa using immunocytochemical detection.

\section{Methods}

Studies were carried out on smears from biopsies of the oral cavity, rectum and stomach (ICD-10K29.3) from seventy patients with chronic gastritis for the detection of Helicobacter pylori (HP) using immunocytochemistry. This technique allows detection of both coccoid and spiral forms of HP.

Results

Our research demonstrated that the stomach was dominated by spiral forms, with coccoid forms being much less common (on average about 5 per cent). There was a quite different distribution of spirals and cocci in the oral cavity and rectum. The oral cavity demonstrated almost exclusively coccoid forms of HP, rarely spiral and HP were detected only in coccoid forms in the rectum.

Bacterioscopic investigation of gastrointestinal mucosa carried out via direct immunocytochemical staining clearly shows that HP - mucosal colonization occurs in the stomach (typically more than 50 helical cells in a single field of view), and that HP exits the body through the oral cavity and intestinal tract (5-10 cocci forms in 300 fields of view). Results of HP detection in the oral cavity and rectum corresponded with HP detection in the stomach in 80 per cent and 83 per cent of cases, respectively.

\section{Conclusion}

Immunocytochemical observation of HP in the oral cavity, stomach and rectal mucosa suggests that HP bacterial cells enter the gastrointestinal tract as coccoids, colonize stomach mucosa in vegetative spiral form and leave as coccoid forms. Thus, our data from direct bacterioscopy strongly supports the hypothesis that HP infection spreads and contaminates the gastrointestinal tract through its coccoid forms.

\section{Key Words}

Helicobacter pylori, coccoid forms, immunocytochemistry, oral cavity, stomach, rectum 


\section{What this study adds:}

\section{What is known about this subject?}

Helicobacter Pylori (HP) is associated with inflammatory diseases of the stomach. HP exists in the human gut in both spiral and coccoid forms.

\section{What new information is offered in this study?}

Immunocytochemical staining allows identification of HP in spiral and coccoid forms in the stomach, oral cavity and rectum. The stomach is dominated with spiral forms of HP, less so in the oral cavity. Bacterial cells of HP were only seen in coccoid form in the rectum.

3. What are the implications for research, policy, or practice?

HP infection spreads and contaminates the human gut through its coccoid forms. Non-invasive immunocytochemical testing (in the oral cavity and rectum) can be recommended for HP detection and estimation of HP survival in coccoid form after treatment.

\section{Background}

Colonization of gastric mucosa by vegetative bacterial cells Helicobacter pylori (HP) plays an essential role in the development of stomach disease and duodenal ulcers. However, bacterial cells of HP were found not only in the stomach, but also in other parts of the gastrointestinal tract. Numerous studies that conducted the diagnosis by gene testing, culture, urease methods and even by electron microscopy, show the presence of HP in the oral cavity. ${ }^{1-13}$ HP was also found in faeces. ${ }^{5,6,14-18}$ It was established that HP bacterial cells in the oral cavity and in the stomach are genetically identical. $^{19,13}$

We performed immunocytochemical studies of HP in smears from gastric biopsies as well as in smears from the surface of the gingival sulcus and rectum in the same patients.

This article presents data on the prevalence of spiral and coccoid forms of $\mathrm{H}$. pylori in the gastrointestinal tract and compares the results of immunocytochemical detection of $\mathrm{HP}$ in the mouth and rectum with the detection of HP by using the same method in gastric biopsies obtained during endoscopy.

\section{Method}

The study included seventy patients $(n=70)$ who were treated at the medical centre of Nikiforov Russian Centre of Emergency and Radiation Medicine, EMERCOM.
Helicobacter pylori (HP) were assessed in male (49 per cent) and female (51 per cent) patients with chronic gastritis and erosive ulcerative diseases of the stomach and duodenal bulb by using the immunocytochemical method of detection. Each of the seventy patients were examined for $\mathrm{HP}$ in the oral cavity, stomach and rectum.

Swabs from the surface of the gingival sulcus, taken with a sterile disposable brush, were used for HP studies in the oral cavity. The brush biopsies were applied to a degreased object-plate in a thin layer, so that the obtained cytological swabs were always presenting bacterial plaque and gum epithelium. The collection of material from the oral cavity was performed in the morning on an empty stomach before morning teeth brushing.

HP studies of gastric mucosa (GM) were performed in smears, derived from gastric biopsies during gastroscopy.

HP studies from the rectum were also obtained by brush cytology swabs. For this purpose, a urological soft probe was inserted into the rectum immediately after defecation, turning it in a rotational motion, and then transferring the locally applied material onto an object-plate. As a result, the obtained swabs are always presenting faecal material as well as epithelial mucosa of the rectum.

The material for all three types of studies was collected from patients in parallel over a two to three day period.

Cytologic smears were fixed with a mixture of alcoholacetone in a 1:1 ratio for 10 minutes, air dried, and endogenous peroxidase was inactivated with 1 per cent sodium azide (Merck) for 15 minutes. Then, washed in two shifts bidistilled water and left for five minutes in Tris- $\mathrm{NaCl}$ buffer ( $\mathrm{pH}$ 7.6). After that, the field for immunocytochemical analysis was surrounded with a hydrophobic pen (DakoCytomation) prior to the application of pig serum (Novocastra). The rabbit polyclonal antibodies (NCL-HPp, Novocastra), directed against cytoderm antigens of Helicobacter pylori, were applied after incubation with preimmune serum (30 minutes at room temperature), and the preparation was incubated for an hour at $+37^{\circ} \mathrm{C}$. At the end of labeling with the first antibodies, the preparations were carried out in two shifts of the buffer for five minutes and pork biotinylated antibodies (DakoCytomation) directed against rabbit antibodies were applied. The second antibody preparations (coverslip impression) were incubated for 15 minutes at room temperature. The next step of the immunocytochemical procedure was preceded by washing preparations in two shifts buffer, coating was for 10 
minutes at room temperature in an imaging system that consists of a soluble complex - avidin and biotinylated horseradish peroxidase (DakoCytomation). 3,3'diaminobenzidine (DAB) in the format of Novocastra, was used as a substrate for the manifestation of immunocytochemical reaction. Coverslip impression was additionally stained with haematoxylin. It should be noted that the immunocytochemical verification result for $H$. pylori infection when using the first rabbit polyclonal antibody from "DakoCytomation" was consistent with the result when using the first rabbit polyclonal antibodies from "Novocastra".

The principle of immunocytochemical method used in this study is based on the specific binding of antibodies to antigens of the cell wall of $H$. pylori (HP), which is subsequently detected using imaging systems, based on the affinity of avidin to the biotinylated antibody molecules. As a result of immunocytochemical reaction between peroxidase bound to avidin and a dye substrate, only bacterial cells that have antigens specific to $\mathrm{HP}$, will have the characteristic colour.

Analysis of the preparations (coverslip impression) was carried out using the immersion objective $(\times 100)$ on a microscope Leica DM 4000 B to determine the HP in the smears taken from the surface of the gingival sulcus and in smears from the rectum viewed at 300 fields of view. A positive result of infection by bacterial cells of HP was recorded if this detected at least five bacterial cells with species-specific antigens of HP.

\section{Results}

HP bacterial cells were stained with diaminobenzidine in colour from light brown to dark brown in gastric biopsies from the antrum with a positive immunocytochemical reaction. The spiral shape of HP in the stomach was seen in the vast majority of cases (Figure 1a-d). Dimensions of spiral forms of HP varied from $3-5 \mathrm{~mm}$ in length (including the flagellum), and around 0.5 microns in diameter. HP coccoid forms showed brown staining with $D A B$ due to presence of species-specific antigens, mono and diplococcus forms, having sizes ranging from 0.5 to 1 micron in diameter which were perfectly circular shape and were uniformly stained with slightly higher intensity than the spiral form of HP.

It is important to note that the coccoid forms of HP in the antrum of the stomach were found on average in 5 per cent of the total microbial population of HP bacterial cells that produce seeds in the GM. The frequency of HP detection in the $\mathrm{GM}$ in the antrum was 60 per cent.
It should also be noted that the artifacts resulting from the preparation of smears and after immunocytochemical staining are sometimes very similar in appearance to the coccoid forms of HP. In fact, usually these are the flagella, torn apart and lying separately, or just fragments of already dead and disrupted bacterial cells of HP. They are stained with $D A B$, as they are likely to bear the antigens of the cell wall to which immunocytochemical reaction was caused. Typically, "coccoid artifacts" are less than $0.5 \mathrm{~mm}$ in size and have irregular shape, which differs them greatly from the true HP cocci.

In the smears after immunocytochemical staining together with brown bacterial HP cells other bacterial cells (bacillus, rod-shaped bacteria, streptococcus, etc.), stained with haematoxylin in light gray-pink tones were seen.

Transient U- shaped forms of HP could be always met along with the spiral and coccoid forms. It is considered that spiral forms can transform into coccoid forms through these transient U-shaped morphological forms, i.e., actually that is the bacillary-coccoid transformation. Along with single coccoid HP forms after immunocytochemical staining diplococcus forms of HP were found in cytological smears. Thus, cytological smears stained with immunocytochemical method presented all the stages of bacillary-coccoid transformation - spiral shape - intermediate U-shape transient diplococcal variants - and finally cocci.

In contrast to gastric mucosa samples, the vast majority of cases in the studied samples from the oral cavity of bacterial cells with HP antigens were coccoid and U-shaped bacteria (Figure 2a and b). There were no differences in coccoid and U-shaped forms observed in GM. Additionally, in the oral cavity, we found bacteria with positive immunocytochemical staining for species-specific HP spiral forms antigens and with flagella (spiral shape of HP). However, they appeared much less frequently in contrast to the antrum with the coccoid forms of HP (Figure $2 b$ and $c$ ).

Bacterial cells with HP antigens were seen on average in 62.8 per cent of cases from smears of plaque material and epithelium from the gingival sulcus.

We did not see spiral forms of HP or bacteria with a positive immunocytochemical reaction to HP antigens with the same spiral shape and flagella (or at least a spiral shape) as the material from the rectum (in the epithelium of mucosa and in faeces) over the course of the study. We detected only coccoid bacterial cells in the rectal swabs from positive HP- 
antigen (Figure 3), seen in 61.4 per cent of the examined patients

It is important to note that we encountered the coccoid forms of HP in the material from the rectum in two ways. The first variant was small (0.2-0.5 micrometers), uniformly stained and similar to gastric biopsies of gastric mucosa (Figure 3a). In the second variant (embodiment), the HP coccus positive-antigen were larger (up to 2 microns), sometimes oval shape and less intensely dyed with the lumen in the center (Figure 3c).

The frequency of HP detection in the studied group of patients by immunocytochemical method was 60 per cent in GM from the antrum, 62.8 per cent in the smears from the oral cavity and 61.4 per cent in the smears from the rectum (Table 1). It could appear that all three options are coincidental, since they show nearly the same results, i.e., about 60 per cent, and they were statistically indistinguishable from each other $(p>0.05)$. However, there were 35 patients from 70 studied patients with positive HP from all three locations, and 20 patients with negative HP. Therefore, the results of immunocytochemical studies of HP in the oral cavity, stomach and rectum have completely coincided in 50 of 70 patients, i.e., 71.4 per cent of cases. In other cases, HP was detected (or vice versa - not detected) in one of three examined locations. For example, HP was identified in the oral cavity, and not identified in the stomach and in the rectum.

We have taken the direct bacterioscopic method for detection of HP in gastric biopsy specimens obtained during endoscopic examinations as the "gold standard", in order to consider separately whether oral and rectal options for identifying HP coincide with the identification of HP in gastric biopsy specimens. There were 35 in 70 patients positive for HP simultaneously in the oral cavity and stomach, and 20 in 70 patients negative for HP. Complete coincidence was for 55 of 70 patients and, therefore, it can be assumed that the immunocytochemical method for HP detection in the oral cavity is informative in 78.6 per cent of cases. Cases where HP was identified in the stomach and not in the oral cavity were rarely identified and accounted for 5 of 70 patients (7.1 per cent). Conversely, cases where HP was not identified in the stomach and detected in the oral cavity accounted for 7 of 70 patients (10 per cent).

Almost the same pattern was found between the endoscopic "gold standard" and the identification of HP in the material from the rectum. Complete concordance of these two methods (37 of $70 \mathrm{HP}$-positive patients and 20 of
70 HP-negative patients) was recorded in 81.4 per cent of cases. We found out that from 70 studied cases, five were non diagnostic (HP were identified in the stomach, and not found in the rectum).

Oral and rectal detection options of HP in the studied group of patients coincided with each other at 90 per cent. Seven cases out of 70 were such that when one location in the HP has been identified, the other was not.

The results of the analysis of the operational characteristics of the immunocytochemical HP test in the mucous oral cavity and rectum in comparison to gastric biopsy specimens obtained during endoscopic examinations are presented in Table 2.

\section{Discussion}

Below, we consider all options for the detection of HP in the oral cavity, antrum of the stomach and rectum.

The situation where HP was detected or not detected in all three examined localizations in the gastrointestinal tract does not require much comment. It can be assumed for those cases that either the helicobacter infection is present in the gastrointestinal tract, or there is no helicobacteriosis of the digestive tract.

In our view, it is quite an acceptable variant, when HP was found in the oral cavity, and not detected in the stomach and intestines. HP Bacterial cells in this embodiment produce seeds only in oral cavity. Perhaps their coccal forms are swallowed at first, and then they go transiently through gastrointestinal tract, without stopping in the stomach and without colonizing the GM to come out of the rectum.

The possible option, where the HP bacterial cells were not identified in the GM of the antrum and were found in the material from the rectum, could arise in some cases, as HP produce seeds in the body of the stomach and not in the antrum. In the present study, we examined only gastric biopsy specimen of the antrum.

The other variant, where HP bacterial cells were only detected in the stomach and not in the oral cavity or in the material from the rectum, can be explained by the fact that HP bacterial cells were not available and were deep in the dento-gingival pockets in the oral cavity at the time of obtaining the material. Additionally, the material from the rectum with a small number of HP bacterial cells may not be detected if the smear was poor (contained little material). 
Recall that the first antibodies used are the polyclonal antibodies to the cell wall of HP. Thus, we used polyclonal antibodies from the company Novocastra in this work, which were adapted and provided a guarantee for studying gastric biopsy specimens. ${ }^{20}$ Therefore, we cannot exclude that the false positive result of HP detection in the mucosa of the mouth and rectum (hyper diagnostic per cent) was due to cross-reactivity of polyclonal antibodies to the antigens of bacteria, which produces seeds on these mucous membranes that are not related to the Helicobacter pylori bacteria. In connection with the later circumstance of improving HP immunocytochemical detection method, it is still possible to use monoclonal antibodies specific species of HP antigens.

Several researchers have evaluated and compared different types of diagnostic methods for both direct methods (such as histopathology, immunohistochemistry, rapid urease test and culture) and indirect methods (such as antibody-based tests (serology and urine test), urea breath test, and stool antigen test as well as newer modalities such as polymerase chain reaction testing that provide additional virulence and antibiotic sensitivity profiling. They compared accuracy, simplicity, invasiveness, resources and clinical situation that it can be applied to, depending on the prevalence of HP in the area and patient circumstances, etc. Therefore, the indirect methods are also good to determine HP infection. ${ }^{21-}$ ${ }^{24}$ Combining the results of two or more tests may give a better strategy in the routine clinical situation to get better results. $^{21}$

According to our data presented in this study, HP was detected in the oral cavity by using immunocytochemical method in 60 per cent of cases (residents of St. Petersburg). And data in the literature review reveals that the HP urease detection test rate in Pakistani patients with chronic gastritis in the oral cavity was 92.3 per cent. ${ }^{25}$ The presence of HP in the oral cavity was found in 54.1 per cent ${ }^{4}$ and in 69.7 per cent in groups of individuals studied in culture. ${ }^{26}$ The lowest frequency detection of HP in the oral cavity was seen in the PCR method - 35.1 per cent, ${ }^{10}$ and $12.5-37.5$ per cent. $^{1}$

Due to high prevalence of HP positive patients, the authors recommend using sensitive, noninvasive methods for detecting $\mathrm{HP}$, quantification, with partial genotyping of $H$. pylori such as stool based ddPCR assays, that can correlate with the presence of cagA virulence gene ${ }^{27}$ or using simple methods for detecting HP in stool such as chemiluminescence immunoassays, ${ }^{28}$ 13C-urea breath test, $^{29}$ immunochromatography in the sandwich format detection of $H$. pylori cell wall antigens at concentrations as low as $0.3 \mu \mathrm{g} / \mathrm{mL}$ in aqueous solution and a suspension of a clinical sample of faeces in 10 minutes $^{30}$ or applying HP stool antigen test before the eradication treatment against HP is initiated and even before doing endoscopy. ${ }^{18}$

Rafeey and Nikvash compared the ELISA HP stool antigen test (HpSA) with morphological examination of HP gastric biopsy specimen. According to the study, done by these authors, it appeared that 62 HP positive and 34 HP negative patients in their histological findings were identified as positive and negative for HP antigens in stool i.e., 34 and 27 patients, respectively. Thus, the specificity and sensitivity of the HpSA and in comparison with the "gold standard" were 54.8 per cent and 79.4 per cent, respectively. Based on that, the authors concluded that HpSA can be used for mass screening of HP. ${ }^{31}$

Another research study by Korkmaz et al. established HP colonization in the stomach (which was 50.6 per cent) by using urease test, and detecting HP in faeces by using Genx $H$. pylori stool antigen card method that was based on immunochromatographic assay, which accounted to 19.7 per cent in the same time in the same group of patients, thus giving less reliable results. ${ }^{15}$

Aktepe et al. studied a group of 132 patients with chronic gastritis in the stomach and faeces. HpSA test positive presence of HP in stool was detected in 48.5 per cent. PCRtest's per cent of HP detection in stomach was 74.2 per cent. The frequency of HP detection by FISH-test in stomach was 61.4 per cent. Rarer identification of HP revealed with PCR-stool test in faeces was 21.2 per cent. $^{32}$

Another study could prove a good detection of Helicobacter pylori stool assay using immunochromatographic testing device LFD in Chinese population. ${ }^{33}$ However, immunochromatographic faecal antigen test is not recommended to be used for primary diagnosis in acute infection. ${ }^{34}$ None of the chromatographic tests are as accurate and reliable as urease breath test, rapid urease test and histology or positive culture in isolation. ${ }^{35}$

The Immunohistochemistry method is also highly recommended for basic HP biopsies ${ }^{36}$ or for clinically susceptible, nonactive chronic gastritis cases when the usual stain based HP detection is negative, ${ }^{37}$ or in low density or coccoid forms of HP. ${ }^{38}$

Immunocytochemistry study of HP in stool can take on the role of the reference method in the development and 
testing of other equally informative and express methods of screening for $\mathrm{H}$. pylori. The arsenal of those noninvasive techniques, employing antibodies to HP, continues to expand $^{39-41}$ as well as using immunochromatography. ${ }^{15,42}$

In contrast to the informative detection of HP in the stool, data from experts on the diagnostic significance of detecting HP in the oral cavity and its association with gastric infection is contradictory. ${ }^{3,11,13,26,43-45}$ It may be true that HP test in the oral cavity is not quite adequate for the primary diagnosis of HP-associated diseases, caused by Helicobacter pylori infection in the stomach. According to our observations, Helicobacter pylori infection can only be found in oral form (i.e., in the absence of HP in the stomach). However, considering re-infection of the gastric mucosa by HP bacterial cells, preserved in the oral cavity after anti $H$. pylori eradication therapy, it is practically important to identify HP in the oral cavity for sensible therapy of HP acid-associated diseases, as well as the reliability of monitoring eradication efficiently. ${ }^{2,32,45}$ It is shown that bacterial cells with HP antigens in the oral cavity are maintained in patients who have not attained eradication after the antibiotic therapy course against $H$. pylori. $^{46,13}$ Increasing the standard course of eradication concomitant readjustment of the oral cavity probably increases the effectiveness of antibiotic treatment of $H$. pylori. The immunocytochemical method may also be recommended to substantiate the use of such readjustment, in order to detect $\mathrm{HP}$ that allows visualizing the spiral and, as a rule, coccoid forms of HP in dental plaque and gingival epithelium.

Finally, we would like to underline that in the modern literature, we could not find any information about the observations of the bacterial cells HP directly in material from the rectum with microscopy techniques. To our knowledge, our report documents microphotographs of the bacterial cells HP in faeces from the rectum for the first time (Figure 3).

Direct bacterioscopic investigation that was carried out via immunocytochemical staining of gastrointestinal mucosa clearly shows that HP - mucosal colonization occurs in the stomach (typically more than 50 helical cells in a single field of view). HP transits through the oral cavity and intestines (5-10 cocci forms in 300 fields of view. Our research found that the stomach is dominated by spiral forms and coccoids were much less common (on average about 5 per cent). In the oral cavity and rectum, we found a quite different distribution of spirals and coccoids. The oral cavity was mostly full of coccoid forms of HP and rarely spiral forms.
Helicobacter Pylori was detected only with coccoid forms in the rectal mucosa. Therefore, we can conclude that HP enters the human body through the oral cavity in the coccoid form; colonizes the gastric mucosa; vegetating spiral forms and leaves the human body in the form of coccus. Probably coccoid HP forms are forms of conservation and existence of HP outside the human body. These pure coccoid forms of HP can cause gastritis, same as spiral forms of HP but to a lesser extent; ${ }^{47}$ with another other study showing that coccoid forms contain high levels of proteins that can be involved in virulence and carcinogenesis, more so than spiral forms of HP. ${ }^{48}$ This confirms the assumption of the other authors that Helicobacter pylori infection spread occurs through its coccoids in the faecal-oral route. ${ }^{5,19,25,48,49}$

\section{Conclusion}

In conclusion, immunocytochemical detection of HP is an effective tool for diagnosing HP in both coccoid forms and spiral forms.

Knowing the distribution of HP in the body either in the oral cavity, stomach or rectum as well could be helpful in increasing the effectiveness of treatment plans against HP.

\section{References}

1. Al-Hawajri AA, Keret D, Simhon A, et al. Helicobacter pylori DNA in dental plaques, gastroscopy, and dental devices. Dig Dis Sci. 2004;49(7-8):1091-4.

2. Anand PS, Nandakumar K, Shenoy KT. Are dental plaque, poor oral hygiene, and periodontal disease associated with Helicobacter pylori infection? J Periodontol. 2006;77(4):692-8.

3. Chisazi MT, Fattahi E, Farahani RM, et al. Helicobacter pylori in the dental plaque: is it of diagnostics value for gastric infection? Med Oral Patol Oral Cir Bucal. 2006;11(4):E325-8.

4. Czesnikiewicz-Guzik M, Bielanski W, Guzik TJ, et al. Helicobacter pylori in the oral cavity and its implications for gastric infection, periodontal health, immunology and dyspepsia. J Physiol Pharmacol. 2006;6:77-89.

5. Ismail H, Morgan C, Griffiths $P$, et al. A newly developed nested PCR assay for the detection of Helicobacter pylori in the oral cavity. J Clin Gastroenterol. 2016;50(1):17-22. doi: 10.1097/MCG.0000000000000310.

6. Kabir S. Detection of Helicobacter pylori in faeces by culture, PCR and enzyme immunoassay. J Med Microbiol. 2001;50(12):1021-9.

7. Koletzko S, Konstantopoulos N, Bosman D, et al. Evaluation of a novel monoclonal enzyme immunoassay 
for detection of Helicobacter pylori antigen in stool in children. Gut. 2003;52(6):804-6.

8. Mesquita B, Gonçalves MJ, Pacheco P, et al. Helicobacter pylori identification: a diagnostic/confirmatory method for evaluation. Curr Microbiol. 2014;69(3):245-51. doi: 10.1007/s00284-014-0578-8.

9. Ogaya $Y$, Nomura $R$, Watanabe $Y$, et al. Detection of Helicobacter pylori DNA in inflamed dental pulp specimens from Japanese children and adolescents. J Med Microbiol. 2015;64(Pt1):117-23. doi: 10.1099/jmm.0.079491-0.

10. Umeda M, Kobayashi $Y$, Takeuchi $Y$, et al. High prevalence of Helicobacter pylori detected by PCR in the oral cavities of periodontitis patients. J Periodontol. 2003;74(1):129-34.

11. Veiga N, Pereira C, Resende C, et al. Oral and gastric Helicobacter pylori: effects and associations. PLoS One. 2015;10(5):e0126923. doi:10.1371/journal.pone.0126923.

12. Mazaheri Assadi M, Chamanrokh P, Whitehouse CA, et al. Methods for Detecting the Environmental Coccoid From of Helicobacter pylori. Front Public Health. 2015;3:147. doi: 10.3389/fpubh.2015.00147.

13. Yee JK. Helicobacter pylori colonization of the oral cavity: A milestone discovery. World J Gastroenterol. 2016;22(2):641-8. doi: 10.3748/wjg.v22.i2.641.

14. Kim do $H$, Jung HM, Hwang YJ, et al. Culture and polymerase chain reaction of Helicobacter pylori from rectal and terminal ileal fluid after polyethylene glycol (colyte) ingestion in healthy adults with positive urea breath test. Korean J Gastroenterol. 2010;56(1):27-32.

15. Korkmaz H, Findik D, Ugurluoglu C, et al. Reliability of stool antigen tests: investigation of the diagnostic value of a new immunochromatographic Helicobacter pylori approach in dyspeptic patients. Asian Pac J Cancer Prev. 2015;16(2):657-60.

16. Lottspeich Ch, Schwarzer A, Panthel K, et al. Evaluation of the novel Helicobacter pylori clarires real-time PCR assay for detection and clarithromycin susceptibility testing of $H$. pylori in stool specimens from symptomatic children. J Clin Microbiol. 2007;45(6):1718-22.

17. Yari F, Abiri R, Aryan E, et al. Loop-Mediated Isothermal Amplification as a Fast Noninvasive Method of Helicobacter pylori Diagnosis. J Clin Lab Anal. 2016;30(5):464-70. doi: 10.1002/jcla.21880.

18. Saha R, Roy P, Das S, et al. Application of a stool antigen test to evaluate the burden of Helicobacter pylori infection in dyspepsia patients. Indian J Pathol Microbiol. 2016;59(1):66-8. doi: 10.4103/0377-4929.174819.

19. Cai H, Li W, Shu X, et al. Genetic variation of Helicobacter pylori in the oral cavity and stomach detected using thymine adenine cloning in children with chronic gastritis. Pediatr Infect Dis J. 2014;33(1):e1-6. doi: 10.1097/INF.0000000000000017.

20. Ashton-Kay M, Diss TC, Isaacson PG. Detection of Helicobacter pylori in gastric biopsy and resection specimens. J Clin Pathol. 1996;49(2):107-11.

21. Zagari RM, Romano M, Ojetti V, et al. Guidelines for the management of Helicobacter pylori infection in Italy: The III Working Group Consensus Report 2015. Dig Liver Dis. 2015;47(11):903-12. doi: 10.1016/j.dld.2015.06.010.

22. Miftahussurur M, Yamaoka Y. Diagnostic Methods of Helicobacter pylori Infection for Epidemiological Studies: Critical Importance of Indirect Test Validation. Biomed Res Int. 2016;4819423. doi: 10.1155/2016/4819423.

23. Atkinson NS, Braden B. Helicobacter Pylori Infection: Diagnostic Strategies in Primary Diagnosis and After Therapy. Dig Dis Sci. 2016;61(1):19-24. doi: 10.1007/s10620-015-3877-4.

24. Wang YK, Kuo FC, Liu CJ, et al. Diagnosis of Helicobacter pylori infection: Current options and developments. World J Gastroenterol. 2015;21(40):11221-35. doi: 10.3748/wjg.v21.i40.11221.

25. Siddiq M, Haseeb-ur-Rehman, Mahmood A. Evidence of Helicobacter pylori infection in dental plaque and gastric mucosa. J Coll Physicians Surg Pak. 2004;14(4):205-7.

26. Ogunbodede EO, Lawal OO, Lamikanra A, et al. Helicobacter pylori in the dental plaque and gastric mucosa of dyspeptic Nigerian patients. Trop Gastroenterol. 2002;23(3):127-33.

27. Talarico S, Safaeian M, Gonzalez P, et al. Quantitative Detection and Genotyping of Helicobacter pylori from Stool using Droplet Digital PCR Reveals Variation in Bacterial Loads that Correlates with cagA Virulence Gene Carriage. Helicobacter. 2016;21(4):325-33. doi: 10.1111/hel.12289.

28. Ramírez-Lázaro MJ, Lite J, Lario S, et al. Good diagnostic accuracy of a chemiluminescent immunoassay in stool samples for diagnosis of Helicobacter pylori infection in patients with dyspepsia. J Investig Med. 2016;64(2):38891. doi: 10.1136/jim-2015-000004.

29. Kwon YH, Kim N, Lee JY, et al. The diagnostic validity of citric acid-free, high dose (13)C-Urea breath test after Helicobacter pylori eradication in Korea. Helicobacter. 2015;20(3):159-68. doi: 10.1111/hel.12189.

30. Byzova NA, Zherdev AV, Sveshnikov PG, et al. Development of an immunochromatographic test system for the detection of Helicobacter pylori antigens. Prikl Biokhim Mikrobiol. 2015;51(5):520-30.

31. Rafeey M, Nikvash S. Detection of Helicobacter pylori antigen in stool samples for diagnosis of infection in children. East Mediterr Health J. 2007;13(5):1067-72. 
32. Aktepe OC, Ciftçi IH, Safak B, et al. Five methods for detection of Helicobacter pylori in the Turkish population. World J Gastroenterol. 2011;17(47):5172-6. doi: 10.3748/wjg.v17.i47.5172.

33. Lin Z, Cheng S, Yan Q, et al. Development of an immunochromatographic lateral flow device for rapid detection of Helicobacter pylori stool antigen. Clin Biochem. 2015;48(18):1298-303. doi: 10.1016/j.clinbiochem.2015.08.004.

34. Dalla Nora M, Hörner R, De Carli DM, et al. Is the immunocromarohraphic fecal antigen test effective for primary diagnosis of helicobacter pylori infection in dyspeptic patients? Arq Gastroenterol. 2016;53(4):224227. doi: 10.1590/S0004-28032016000400003.

35. Lario S, Ramírez-Lázaro MJ, Montserrat A, et al. Diagnostic accuracy of three monoclonal stool tests in a large series of untreated Helicobacter pylori infected patients. Clin Biochem. 2016;49(9):682-7. doi: 10.1016/j.clinbiochem.2016.01.015.

36. Lash RH, Genta RM. Routine Anti-helicobacter immunohistochemical staining is significantly superior to reflex staining protocols for the detection of Helicobacter in gastric biopsy specimens. Helicobacter. 2016;21(6):581-585. doi: 10.1111/hel.12315.

37. Kocsmár É, Szirtes I, Kramer Z, et al. Sensitivity of Helicobacter pylori detection by Giemsa staining is poor in comparison with immunohistochemistry and fluorescent in situ hybridization and strongly depends on inflammatory activity. Helicobacter. 2017;22(4). doi: 10.1111/hel.12387.

38. Tajalli R, Nobakht $M$, Mohammadi-Barzelighi $H$, et al. The immunohistochemistry and toluidine blue roles for Helicobacter pylori detection in patients with gastritis. Iran Biomed J. 2013;17(1):36-41.

39. Nguyen TV, Bengtsson C, Nguyen GK, et al. Evaluation of a novel monoclonal-based antigen-in-stool enzyme immunoassay (Premier Platinum HpSA PLUS) for diagnosis of Helicobacter pylori infection in Vietnamese children. Helicobacter. 2008;13(4):269-73. doi: 10.1111/j.1523-5378.2008.00598.x.

40. Pourakbari B, Ghazi M, Mahmoudi S, et al. Diagnosis of Helicobacter pylori infection by invasive and noninvasive tests. Braz J Microbiol. 2013;44(3):795-8. doi: 10.1590/S1517-83822013005000052.

41. Kravtsov VY, Grukhin YA. Immunocytochemical study of Helicobacter pylori in the mucosae of the gastric antrum and rectum. Bull Exp Biol Med. 2012;153(3):348-50.

42. Yong KA, Allaker RP, Hardie JM. Morphological analysis of Helicobacter pylori from gastric biopsies and dental plaque by scanning electron microscopy. Oral Microbiol Immunol. 2001;16(3):178-81.
43. Sousa De L, Vasquez L, Velasco J, et al. Isolation of Helicobacter pylori in gastric mucosa, dental plaque and saliva in a population from the Venezuelan Andes. Invest Clin. 2006;47(2):109-16.

44.Zou QH, Li RQ. Helicobacter pylori in the oral cavity and gastric mucosa: a meta-analysis. J Oral Pathol Med. 2001;40(4):317-24. doi: 10.1111/j.16000714.2011.01006.x.

45. Payao SL, Rasmussen LT. Helicobacter pylori and its reservoirs: A correlation with the gastric infection. World J Gastrointest Pharmacol Ther. 2016;7(1):126-32. doi: 10.4292/wjgpt.v7.i1.126.

46. Sarem M, Corti R. Role of Helicobacter pylori coccoid forms in infection and recrudescence. Gastroenterol Hepatol. 2016;39(1):28-35.

47.Zhu D, Sha L, Shen X, et al. Clinicopathological significance of gastric mucosal infection with coccoid Helicobacter pylori. Zhonghua Bing Li Xue Za Zhi. 2014;43(5):326-9.

48. Loke MF, Ng CG, Vilashni Y, et al. Understanding the dimorphic lifestyles of human gastric pathogen Helicobacter pylori using the SWATH-based proteomics approach. Sci Rep. 2016;6:26784. doi: 10.1038/srep26784.

49. Bui D, Brown HE, Harris RB, et al. Serologic evidence for fecal-oral transmission of Helicobacter pylori. Am J Trop Med Hyg. 2016;94(1):82-8. doi: 10.4269/ajtmh.15-0297.

\section{ACKNOWLEDGEMENTS}

The authors would like to acknowledge the Nikiforov Russian Center of Emergency and Radiation Medicine, EMERCOM. Saint-Petersburg, Russian Federation, in particular Yury Groukhin, Alexander Kondrashin, Irina Mikhailova, Sergey Proshin and Vera Ellinidi for allowing to obtain data and patient material.

\section{PEER REVIEW}

Not commissioned. Externally peer reviewed.

\section{CONFLICTS OF INTEREST}

The authors declare that they have no competing interests.

\section{FUNDING}

None

\section{ETHICS COMMITTEE APPROVAL}

The protocol for the research project was approved by the appropriate ethics committee in a meeting at Nikiforov Russian Centre of Emergency and Radiation Medicine EMERCOM as appropriate ethical standards. 
Figure 1A-D: HP in the stomach

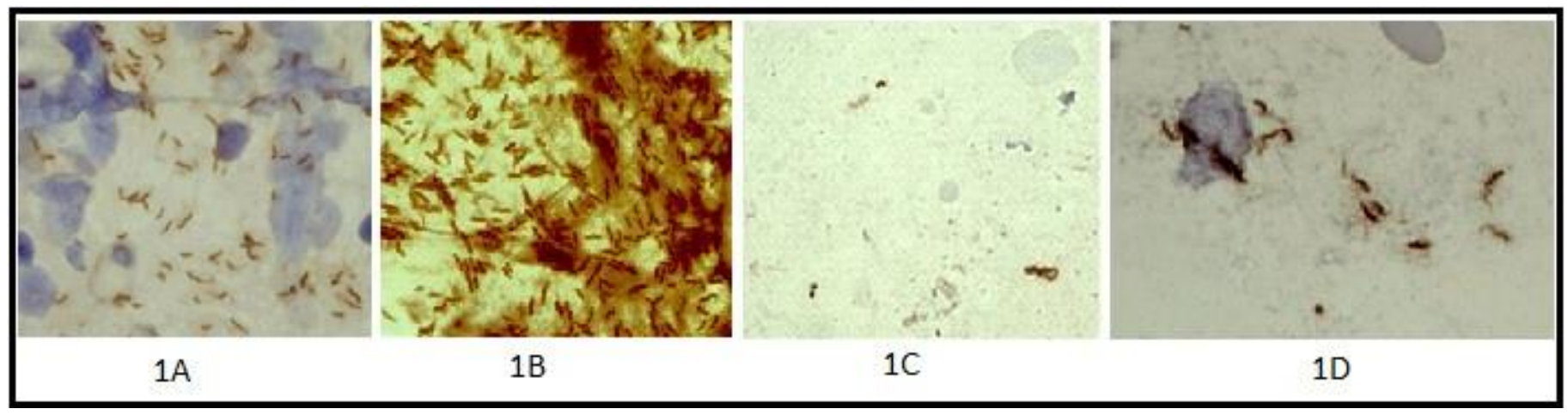

Figure 2A-C: Oral cavity of HP bacterial cells

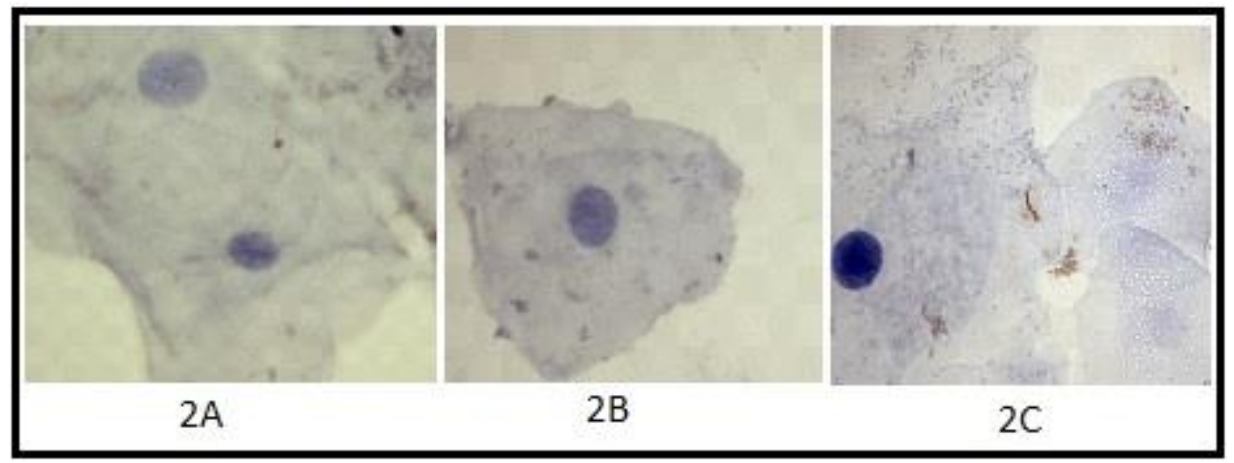

Figure 3A-C: Rectal swabs with positive HP-antigen

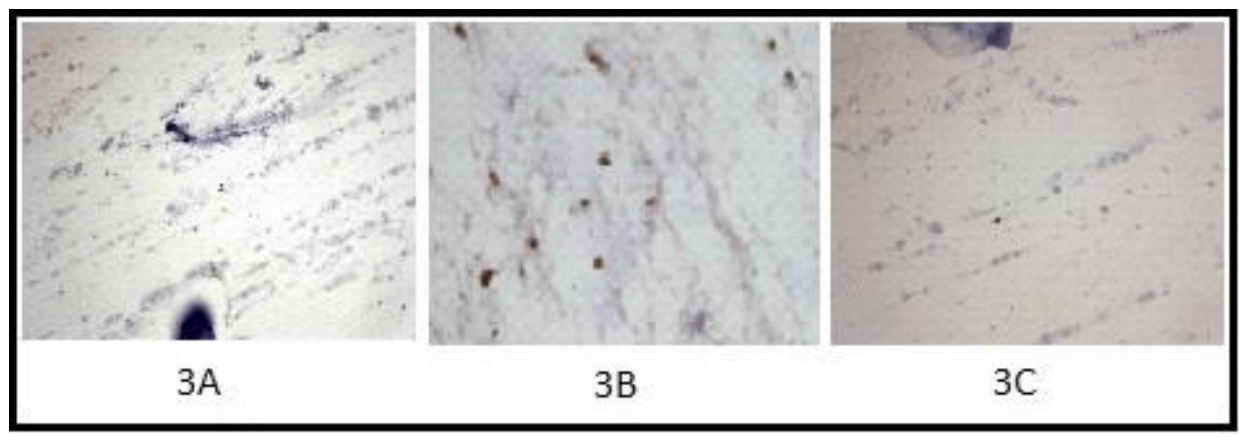

Table 1: Frequency of detection of HP in different locations

\begin{tabular}{|c|c|c|c|c|}
\hline $\begin{array}{l}\text { Number } \\
\text { patients }\end{array}$ & Stomach & $\begin{array}{l}\text { Mucous } \\
\text { oral cavity }\end{array}$ & Rectum & $\%$ \\
\hline 35 & + & + & + & 50.00 \\
\hline 2 & + & + & - & 2.86 \\
\hline 2 & + & - & + & 2.86 \\
\hline 3 & + & - & - & 4.29 \\
\hline 20 & - & - & - & 2857 \\
\hline 2 & - & + & - & 2.86 \\
\hline 5 & - & + & + & 7.14 \\
\hline 1 & - & - & + & 1.4 \\
\hline
\end{tabular}


Table 2: Diagnostic significance of immunocytochemical determination of HP

\begin{tabular}{|l|l|l|l|}
\hline & $\begin{array}{l}\text { Mucous oral } \\
\text { cavity }\end{array}$ & Rectum & $\begin{array}{l}\text { Mucous oral } \\
\text { cavity+rectum }\end{array}$ \\
\hline & & & \\
\hline Sensitivity & 92.5 & 88 & 92.8 \\
\hline Specifity & 75 & 78.5 & 71.4 \\
\hline $\begin{array}{l}\text { Prognostic significance } \\
\text { of a positive result }\end{array}$ & 84.1 & 86 & 82.9 \\
\hline $\begin{array}{l}\text { Prognostic significance } \\
\text { of a negative result }\end{array}$ & 80.7 & 81 & 86.7 \\
\hline
\end{tabular}

